\title{
Nutritional treatment in inflammatory bowel disease. An update
}

\author{
Danila Guagnozzi, Sonia González-Castillo, Antonio Olveira and Alfredo J. Lucendo \\ Department of Gastroenterology. Hospital General de Tomelloso. Tomelloso, Ciudad Real. Spain
}

\begin{abstract}
Background and aims: enteral (EN) and parenteral (TPN) nutrition exert variable therapeutic effects on the induction and maintenance of remission in inflammatory bowel disease (IBD).

This review aims to provide an updated discussion on the complex relationship between diet and IBD.

Methods: medline, Cochrane and Scopus database searches were conducted. Sources cited in the articles obtained were also searched to identify other potential sources of information.

Results: nutritional status is significantly compromised in IBD patients, especially those with Crohn's disease (CD). Apart from restoring malnourishment, dietary components contribute to modulate intestinal immune responses. Nutritional treatment is divided into support therapy and primary therapy to induce and maintain remission through TPN and $\mathrm{EN}$. EN is considered a first-line therapy in children with active $C D$ whereas it is usually used in adult CD patients when corticosteroid therapy is not possible. TPN has limited effects on IBD.

En formula composition, in terms of carbohydrates, nitrogen source and bioactive molecules supplementation, differentially influence on IBD treatment outcomes. Other dietary components, such as poorly absorbed short-chain carbohydrate, polyols, and exogenous microparticles, also participate in the etiopathogenesis of IBD. Finally, new approaches to understanding the complex relationship between IBD and diet are provided by nutrigenenomic.

Conclusion: further long-term, well-powered studies are required to accurately assess the usefulness of nutrition in treating IBD. In future research, the potential role of nutrient-gene interaction in drug trials and specific dietary formula compositions should be investigated in order to incorporate new knowledge about the etiopathology of IBD into nutritional intervention.
\end{abstract}

Key words: Nutrition. Inflammatory bowel disease. Crohn's disease. Ulcerative colitis. Gene-nutrient interaction.

Received: 20-08-2012

Accepted: 26-09-2012

Correspondence: Danila Guagnozzi. Department of Gastroenterology. Hospital General de Tomelloso. Vereda de Socuéllamos s/n. 13700 Tomelloso, Ciudad Real. Spain

e-mail: danila_g@libero.it
Guagnozzi D, González-Castillo S, Olveira A, Lucendo AJ. Nutritional treatment in inflammatory bowel disease. An update. Rev Esp Enferm Dig 2012;104:479-488.

\section{INTRODUCTION}

Inflammatory bowel disease (IBD) encompasses a group of chronic, relapsing inflammatory disorders of the gastrointestinal tract. The major phenotypes of IBD are Crohn's disease (CD) and ulcerative colitis (UC), which are traditionally found at opposite ends of the spectrum.

The relationship between nutrition and IBD is complex and involves several aspects: a) the nutritional status of IBD patients; $b$ ) the therapeutic goals of nutritional treatment, including nutritional therapy as support treatment, the induction of remission, and maintenance treatment; c) the type of formula composition used for nutritional treatment in different studies; and d) the dietary modulation of the intestinal immune response in IBD and its potential clinical implications.

Nutritional therapy in IBD is carried out through total parenteral nutrition (TPN) or enteral nutrition (EN), the latter can be administered both via the nasogastric or oral route $(1,2)$. Several studies have evaluated the effect of certain modifications to the composition of the parenteral and, in particular, enteral diets, including changes in the content of fats, proteins, carbohydrates, bioactive peptides (e.g. glutamine), growth factors, butyrate, omega-3 fatty acids, and antioxidants.

This article reviews current evidence of the efficacy of nutritional therapy in the treatment of IBD, considering the different types of formula composition studied and the role of dietary factors in the etiopathogenesis of the disease. A literature search was carried out for the period between 
1991 and April, 2012. We searched the PubMed, Cochrane, and Scopus libraries using the following individual and combined key words: Crohn's disease, ulcerative colitis, diet, dietary intervention, dietary treatment, enteral or parenteral nutrition, inflammatory bowel disease, nutritional therapy, exclusion diet, nutritional status, nutrigenomics, and dietary risk factors. References cited in the articles obtained were also searched in order to identify other potential sources of information. The results were limited to human studies available in English.

\section{NUTRITIONAL STATUS OF IBD PATIENTS}

The nutritional status of IBD patients is significantly compromised at different levels. The most important causes of malnutrition are decreased food intake (anorexia, abdominal pain, nausea, vomiting, or restricted diets); the malabsorption of nutrients (reduced absorptive surface due to inflammation, resection, bypass, and fistulae); increased intestinal loss due to gastrointestinal disorders; hypermetabolic states; and drug interactions with corticosteroids, sulfasalazine, immunosuppressants, or antimicrobials (3).

In the past, protein-energy malnutrition was very common in IBD patients, affecting 70-80\% of hospitalized patients (4). Malnutrition was more common in CD than in UC patients, with an incidence ranging from $25 \%$ to $80 \%$ (5-7), especially during remission of the disease. This effect could be related to the significant influence of small bowel involvement in patient body weight. The prevalence of protein-energy malnutrition has decreased over the years and recent studies have shown that most adult IBD patients have good nutritional status, although they have significant abnormalities in body composition and some specific nutritional deficiencies (8).

However, protein-energy malnutrition remains one of the major complications in children with IBD. Weight loss is present at diagnosis in up to $90 \%$ of children (9). Growth failure at the time of diagnosis has been reported in 23-88\% of children with $\mathrm{CD}$, being less common in UC patients (10). About $30-40 \%$ of children affected continue to have severe linear growth impairment during the course of the disease, with a final body height below the $5^{\text {th }}$ percentile in $7-30 \%$ of patients. This stems from the fact that CD usually starts at a younger age, impairing growth velocity (11).

\section{THERAPEUTIC GOALS OF NUTRITIONAL TREATMENT IN IBD PATIENTS}

\section{Nutritional support therapy}

It is important to emphasize that undernutrition has a negative impact on the clinical course, rate of postoperative complications (especially anastomotic breakdown), and mortality (sepsis, methicillin-resistant Staphylococcus aureus, pneumonia, and other resistant infections) in IBD patients $(12,13)$. Moreover, undernutrition causes humoral and cellular immunodeficiency, leading to impairment of the mucosal barrier and a greater risk of infection by bacterial translocation (14). Taking all this into account, one of the most important goals of nutritional therapy should be to prevent and treat undernutrition, improving the growth and development of children and adolescents using TPN, $\mathrm{EN}$, or by correcting micronutrient deficiency $(1,2)$.

TPN seems to have a limited role as supportive adjunct therapy in the management of IBD. Still, it may be indicated in some restricted cases, such as in an obstructed bowel that is not amenable to feeding tube placement beyond the obstruction, a short bowel resulting in severe malabsorption or fluid and electrolyte loss that cannot be managed enterally, severe dysmotility in which enteral feeding is impossible, a leaking intestine from high-output intestinal fistula or surgical anastomotic breakdown, in patients intolerant to EN whose feeding cannot be maintained orally, when there is an inability to access the gut for enteral feeding, and in patients undergoing IBD-related bowel surgery in the perioperative period (1,6,15-18).

In addition to the fact that it delivers normal food, EN (with oral nutritional supplements or tube feeding) may be more useful than TPN in the management of undernourished patients with IBD. If the gut can be used safely, EN is actually the preferred feeding method for CD or UC patients needing nutritional support. The advantages of EN include its stimulatory effects on gastrointestinal structure and function as well as its reduced cost compared to parenteral feeding. Oral nutritional supplements (with 500$600 \mathrm{kcal} /$ day) and/or tube feeding improve the nutritional status in adults and especially in children with CD (1921). In fact, $50 \%$ of growth-retarded CD patients cannot regain their body weight through medical therapy alone and must use enteral tube feeding (22). To date, no definitive data has been published on supplementation with oral nutritional supplements in UC patients, who should undergo enteral tube feeding only in exceptional cases (e.g. severe UC without toxic megacolon, colonic perforation or massive colonic bleeding).

Micronutrient deficiency occurs more often in IBD patients with prolonged periods of diarrhea, vomiting, and increased fistula output $(23,24)$. Even when patients seem to be well-nourished, they may show vitamin or mineral deficiencies that need therapeutic correction (lower serum concentrations of water-soluble vitamins, plasma antioxidant vitamins, vitamin E, K, 25(OH)-vitamin D, iron, and other micronutrients). In particular, vitamin $\mathrm{D}$ deficiency is common in CD patients, with levels of parathyroid hormone correlating to bone mineral density in these patients $(25,26)$. Indeed, a randomized controlled study concluded that long-term oral vitamin D supplementation could prevent bone loss in CD patients (27). Finally, it is becoming increasingly apparent that it may have a central role in immune responses and intestinal inflammation (28).

Folic acid deficiency observed in half the number of patients with IBD might be due to difficulties in swallow- 
ing (low-fiber diets), poor absorption or competitive inhibition by certain treatments, such as sulphasalazine or methotrexate (29). The absence of folic acid has been related to the increased risk of colitis-associated carcinogenesis $(30,31)$, as it has a protective effect against high-grade dysplasia and cancer in patients with long-term UC $(32,33)$. Folate deficiency is also linked to the increased incidence of arterial and venous thromboembolic events observed in CD and UC (34), due to hyperhomocysteinemia, a wellknown inducer of hypercoagulability states. Both folic acid and vitamin B12 are essential co-factors in the metabolic route of homocysteine-methionine. Between 20\% and 60\% of patients with $\mathrm{CD}$ and terminal ileitis are deficient in vitamin B12 (14).

\section{Nutritional induction therapy}

Available data so far show that while artificial nutrition seems to play a primary role in the management of patients with active $\mathrm{CD}$, it does not have a primary therapeutic effect in active UC and does not induce clinical remission of this type of IBD.

The use of TPN in the management of active CD is based on theoretical advantages including bowel rest, which could reduce the motor and transport functions of the diseased bowel; reduction of antigenic stimulation, which could eliminate the immunological response to food favored by the presence of impaired intestinal permeability; and stimulation of protein synthesis, which could lead to cell renewal and mucosal healing in the intestine (35). Nevertheless, few controlled clinical trials have been conducted on the use of TPN to induce remission in active CD. The remission rate three months after starting TPN varied from $20 \%$ to $79 \%$, depending on the patient population, length of TPN administration, definitions of remission or recurrence, and concomitant use of medication (36). TPN has also been shown to achieve fistula healing in $43-63 \%$ of patients, accompanied by disease activity reduction and weight gain $(37,38)$. However, TPN does not seem to be better than EN or steroids in terms of efficacy (39). TPN was also associated with an increased risk of adverse events such as sepsis and cholestatic liver disease. All these findings indicate that TPN should not be used as a primary treatment in IBD patients unless they are intolerant to EN and/or steroids (2), but the high efficacy of immunomodulatory and biological drugs advise us against NPT.

Several studies have demonstrated the efficacy of EN in active CD. While EN's mechanisms of action remain unknown, several hypotheses have been proposed, including the ability of nutrients to modulate the commensal microflora and the intestinal immune response by reducing antigen exposure. In fact, EN seems to exert a direct antiinflammatory effect on the intestinal mucosa by reducing IL-6 production and increasing insulin-like growth factor (IGF)-1 production (40). To date, no randomized controlled trials (RCTs) of EN versus a placebo have been conduct- ed (41). However, EN has been proven to be effective in the treatment of the acute phase of $\mathrm{CD}$, achieving remission rates from $20 \%$ to $84.2 \%$ regardless of disease location. The variability in these results may stem from differences among study populations, administration protocols and outcome assessments.

There are some important differences between child and adult $\mathrm{CD}$ regarding the use of EN as induction therapy. Four meta-analyses and a recent Cochrane literature review showed that steroid treatment is more effective than EN in treating adult CD (42-46). In this population, then, EN should not be indicated as a sole therapy unless treatment with corticosteroids is not feasible, as is the case of refractoriness, dependency, intolerance, or refusal of steroid treatment, as well as in patients at high-risk for osteoporosis (1). It is also important to underscore that relapse rates after EN treatment are high (50-90\% at 12 months) in studies carried out in adults (47). In any case, more studies are needed to evaluate the treatment's long-term outcome. Combined therapy (EN and steroids) could be indicated both in undernourished adult patients and in patients with inflammatory intestinal stenosis (1).

In contrast, EN is considered a good first-line therapy for active $\mathrm{CD}$ in children, as it reduces both the need for corticosteroids and abdominal pain due to intestinal stenosis. It has also been demonstrated to cause mucosal healing and improve quality of life $(48,49)$. Furthermore, the RCTs published to date have shown no differences in terms of efficacy between EN and corticosteroids in pediatric patients (50); indeed, EN as a sole therapy exhibited higher efficacy (51) regardless of the formula composition used (52). The beneficial effects of EN on growth and rapid nutritional restitution, along with the reduced number of adverse effects compared to corticosteroid therapy, are particularly significant in children, especially because the use of corticosteroids in this population increases the risk of permanent growth failure, causing 20-30\% of chronically treated children to reach adulthood with an abnormally short stature. However, due to the limited number of retrospective studies available $(53,54)$, questions remain regarding the utility of $\mathrm{EN}$ in pediatric $\mathrm{CD}$. For example, the influence of disease location on patient response to EN requires further evaluation $(47,55)$ as does the relapse rate after initial treatment with EN in long-term outcome studies.

\section{Nutritional maintenance therapy}

Studies evaluating the potential role of nutritional treatment in maintaining clinical remission in IBD patients are scarce.

This is understandable in the case of TPN, which is impractical for remission maintenance in $\mathrm{CD}$ and $\mathrm{UC}$ and therefore not recommended for this indication (2). As a result, no studies evaluating the efficacy of TPN in maintaining CD or UC remission have been published. In the case of EN, only one study has shown that during the fol- 
low-up period, $\mathrm{CD}$ patients in whom remission was induced by parenteral nutrition presented lower recurrence rates if they were kept on EN compared to those who were not (56). Indeed, available evidence suggests that supplementary EN may be effective as an alternative or adjunct therapy for maintaining remission in adult CD patients (57). For example, oral nutritional supplementation has proven beneficial (58-61) in CD patients with persistent intestinal inflammation, as often occurs with steroid-dependent patients. Furthermore, long-term EN supplementation may significantly reduce clinical and endoscopic recurrence after resection in adult CD patients (62). However, in order to confirm these findings, more extensive well-powered studies are needed, especially trials comparing EN with azathioprine and infliximab, which are known to be effective in maintaining remission in $\mathrm{CD}$ patients. Unfortunately, the prospective studies that have been conducted to date evaluating the role of $\mathrm{EN}$ in maintaining remission in pediatric $\mathrm{CD}$ are very limited, making it impossible to reach a conclusion concerning general guidelines on this issue. With regard to UC patients, EN is not recommended for maintaining remission as no clear data exist on the effect of disease-specific formula compositions or nutritional therapy for this purpose $(1,2)$.

\section{TYPES OF FORMULA COMPOSITION FOR NUTRITIONAL TREATMENT}

Different types of formula composition have been used in studies evaluating the efficacy of nutritional therapy in IBD patients through either enteral or parenteral administration.

\section{Protein sources}

Based on the nitrogen source used, EN can be differentiated between: a) polymeric diets that provide nitrogen in the form of whole protein derived from milk, meat, eggs, or soya, along with carbohydrates such as hydrolysates of starch; b) semi-elemental diets (oligopeptides) made by protein hydrolysis to produce a mean peptide chain length of four or five amino acids, which is too short for antigen recognition or presentation; and c) elemental diets (amino acid-based) containing nutrients in simple forms (e.g. amino acids, simple carbohydrates, fats, vitamins, and minerals) that require little or no digestion prior to absorption. These different protein sources can influence the antigen recognition or presentation process and induce or maintain chronic intestinal inflammation. However, a recent meta-analysis showed no difference in efficacy when different formula compositions (polymeric, semi-elemental, or elemental diets) were used to induce remission in CD patients (60). In particular, statistically significant differences were found neither on the basis of the nitrogen source of the diet (elemental, semi-elemental, or polymeric diets) nor on the basis of different protein sources. This leads to the tentative conclusion that protein type does not influence the effectiveness of EN. In light of these findings, polymeric diets should be preferred, as they are less expensive and more palatable than their elemental or semi-elemental counterparts.

\section{Glutamine supplementation}

Glutamine is an essential amino acid with trophic effects on the intestinal mucosa. Glutamine-supplemented food seems to minimize the impairment of intestinal permeability, protect against intestinal mucosal atrophy, and improve nitrogen balance (63). In animal models, glutamine supplementation reduces intestinal damage and improves disease behavior. Several RCTs have been conducted to evaluate the efficacy of glutamine supplementation in enteral or parenteral nutrition treatment in humans (64-66); however, none have been able to demonstrate any additional benefits for the glutamine-supplemented groups.

\section{Fat composition}

Several different formula compositions have been studied to evaluate the influence of the quantity and type of fat (fish oil or short chain fatty acids) on the outcome of IBD patients, particularly with regard to $\mathrm{CD}$. The use of diets with a very low fat content $(0.6 \%-1.3 \%$ of total calories) has been associated with good results in comparison to diets with a very high fat content (12\%-30\% of total calories), particularly in the presence of large amounts of linoleic acid (67-69). While an non-significant trend favoring very low fat and/or very low long-chain triglyceride content was demonstrated in CD patients in a recent Cochrane Review, larger trials are needed to explore the significance of this finding (64).

The benefits of fish oil (n-3 fatty acids) in treating inflammatory diseases such as psoriasis and rheumatoid arthritis have already been demonstrated. Experimental models of dextran sulfate sodium-induced colitis also support a positive role for $\mathrm{n}-3$ fatty acids supplementation (70). Likewise, in patients with IBD, fish oil supplementation was found to reduce both inflammation and the necessary dosage of anti-inflammatory drugs while promoting weight gain.

Several trials evaluated the efficacy of oral $n-3$ fatty acid supplements to maintain remission in $\mathrm{CD}$ and $\mathrm{UC}$ patients. A recent meta-analysis concluded that $\mathrm{n}-3$ fatty acids may be effective for remission maintenance in $\mathrm{CD}$ patients when administered as enteric coated capsules, but showed no benefits in UC patients (71). In any case, the data are insufficient for recommending their routine use (1). No data exist to date on the efficacy of administering $n-3$ fatty acid supplements via the parenteral route in humans.

Short-chain fatty acids (SCFA) such as butyrate serve as an energy source for colonocytes; a reduction in the levels of these substances has been proposed as a possible 
mechanism in the pathogenesis of IBD. Several studies evaluating the efficacy of topical administration of butyrate instead of corticosteroids or mesalazine to induce remission in UC patients have found a comparable remission rate (72). The efficacy of using a different administration route (parenteral or enteral) has not yet been established, nor has this topical treatment been proven effective in CD patients with colonic localization.

\section{Carbohydrate composition}

It has been suggested that a diet high in carbohydrates promotes the development of CD. Two studies evaluated a specific carbohydrate diet limiting complex carbohydrates (disaccharides and polysaccharides) and eliminating refined sugar altogether $(73,74)$, but the effect of a low carbohydrate diet on the clinical course of IBD has yet to be definitively demonstrated.

\section{Growth factors}

The addition of bioactive peptides to enteral diet formulas may be beneficial due to their specific growth factor effects and anti-inflammatory actions. Three uncontrolled studies examined the value of a transforming growth factor- $\beta_{2}$ (TGF$\beta_{2}$ )-enriched formula in pediatric CD patients (75-77). All the study subjects received the TGF- $\beta_{2}$ diet for 8 weeks as their sole nutrition source, followed by a 4-week period of controlled reintroduction of normal food. The TGF- $\beta_{2}$ diet was effective in inducing remission $(79 \%)$ and mucosal healing while reducing the levels of inflammatory markers (erythrocyte sedimentation rate and C-reactive protein). However, the relapse rate was high following remission achieved through nutritional therapy and only one-third of the children agreed to use it. So far, no studies have addressed the role of polymeric diets enriched with TGF- $\beta_{2}$ as adjuvant therapy in achieving and maintaining IBD remission.

\section{Exclusion diet}

Several studies have shown that food sensitivity occurs in some CD patients. The most common intolerances observed were against cereals, dairy products, and yeast (78). However, food intolerance is not as frequent in CD patients as claimed by several previous studies and its occurrence and intensity are variable (79). While some studies have suggested that exclusion diets based on daily reintroduction of a single food type could be a useful intervention in active $\mathrm{CD}$, one published study showed high relapse rates $(62 \%)$ after 2 years $(78,80)$. In fact, food sensitivity is of such insignificant importance that it does not warrant putting all patients through the inconvenience of elimination diets.

Several digestive disorders affecting the small bowel, including $\mathrm{CD}$, associate an increased intestinal permeability, which lead to detection of increased serum levels of immune complexes of IgE and IgG anti-IgE autoantibodies, when compared to healthy controls $(81,82)$. However, autoimmune type I allergy to cellular or diet constituents does not seem to be of significance for IBD (83). In contrast, nutritional intervention based on circulating IgG antibodies against food antigens showed effects with respect to stool frequency in the sole published study assessing this intervention (84). Any case, the mechanisms by which IgG antibodies might contribute to disease activity remain to be elucidated.

In conclusion, the aforementioned modifications to enteral diets, elemental diets, or general diets have not yet been proven to have any advantage over standard polymeric diets. Further well-powered studies are needed to evaluate specific formula compositions such as growth factor-enriched diets.

\section{DIETARY MODULATION OF THE INTESTINAL INFLAMMATORY RESPONSE IN IBD AND FUTURE CLINICAL IMPLICATIONS}

While the etiology of IBD remains unknown, it has been suggested that it entails enhanced systemic and mucosal immunological reactivity against gut bacterial antigens resulting from complex interactions between the environment and a patient's genetic makeup (85). This immune reactivity seems to be due to a "loss of tolerance" to autologous enteric flora, resulting in an inappropriate immune response, which in turn leads to the development of a chronic inflammatory process in the intestinal mucosa. In fact, under normal circumstances there are complex interactions between commensal intestinal bacteria, dietary antigens, and the immune system that regulate the maintenance of immune tolerance that seems to be impaired in IBD patients $(85,86)$. Alteration of the composition and function of intestinal micobiota could lead to increased stimulation of the intestinal immune system, epithelial dysfunction and greater permeability of the mucosa, and accordingly, the correct characterization of the components of this microflora and the definition of their functions are vital in order to consider probiotic treatment for IBD $(87,88)$. Probiotics have shown to be as effective as mesalazine in preventing relapses in patients with $\mathrm{UC}$ and in the treatment of pouchitis. Efforts have also been made to identify dietary components (prebiotics) which are capable of regulating the bacterial composition, or which have a trophic effect on the intestinal epithelium. In fact, shortchain fatty acids (butyrate, propionate and lactate) result from the fermentation of fiber by bacterial species in the colon (Bifidobacterium, Eubacterium and Lactobacillus), which promote the good functioning of the mucosa (89), as demonstrated in patients with UC $(90,91)$.

As a source of luminal antigens, the diet is an important factor in the immunopathogenesis of IBD, but whether it plays a primary role in the etiology of IBD or a secondary role in maintaining intestinal inflammation has yet to be definitively established (Fig. 1). 


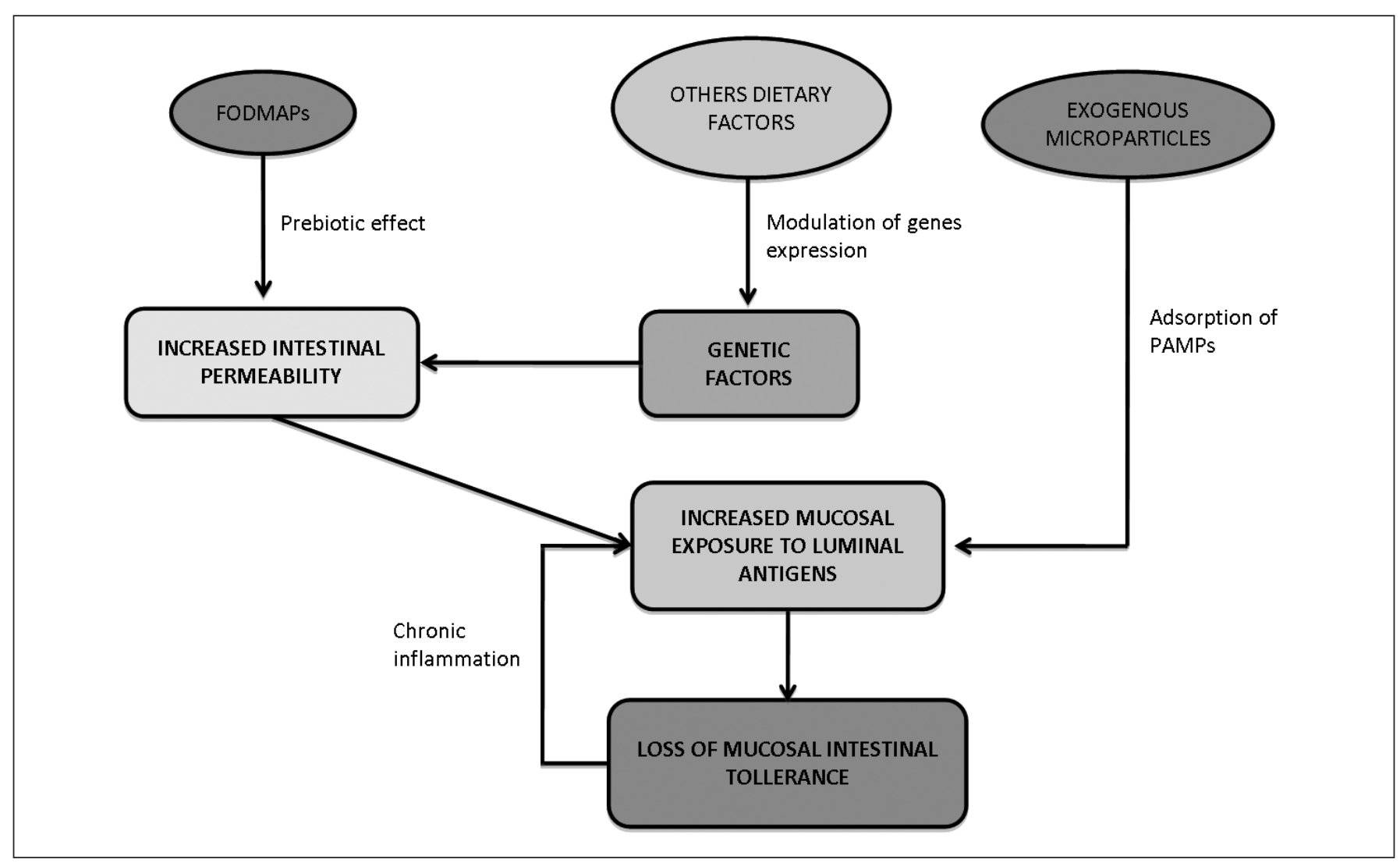

Fig. 1. Role of dietary factors in the etiopathogenesis of inflammatory bowel disease. FODMAPs (fermentable oligo-, di-, and mono-saccharides and polyols), exogenous microparticles, and other dietary factors through different mechanisms -modulation of gene expression, prebiotic effects with increased intestinal permeability, and adsorption of PAMPs (pathogen-associated molecular patterns)- cause increased mucosal exposure to luminal antigens, predisposing patients to a loss of tolerance in the intestinal mucosa, which leads to chronic inflammation.

That being said, there is evidence to suggest that dietary factors may play a primary role in the etiology of IBD. Since the mid- $20^{\text {th }}$ century, the incidence of IBD in general and CD in particular has risen in Western Europe and North America from being a rare condition to one that affects up to $0.2 \%$ of the population (92). This rise in the incidence and prevalence of IBD has paralleled the social and economic development of the affected populations; the adoption of this "Western lifestyle" has included changes in our daily lives, including our dietary intake (93). Several dietary factors have been documented as being associated with $\mathrm{CD}$ pathogenesis, such as the quantity and quality of fat intake; fast food ingestion; and total protein, energy, and sugar intake (94). However, the validity of these findings remains uncertain as they have not been reproduced; moreover, conflicting results have been reported.

\section{The FODMAP hypothesis}

Some evidence suggests that several dietary factors such as poorly absorbed short-chain carbohydrates and polyols (known as FODMAPs -fermentable oligo-, di-, and monosaccharides and polyols) may play a role in the etiopatho- genesis of CD. The common dietary sources of FODMAPs are fructose, fructans, lactose, polyols, and galactooligosaccharides. They all seem to increase intestinal permeability, which is a predisposing factor to the development of $\mathrm{CD}$ in genetically susceptible hosts. The FODMAP hypothesis may thus help explain the etiopathogenesis of CD (94) in that intestinal barrier inefficiency could lead to increased mucosal exposure to luminal pro-inflammatory molecules and micro-organisms and to subsequent potential modulation of mucosal immune responsiveness (95). There are three main lines of evidence for the involvement of FODMAPs in the pathogenesis of CD:

1. The intake of FODMAPs is increasing in Western societies;

2. The association between an increased intake of sugars and the development of CD;

3. Excessive intake of FODMAPs creates conditions in the bowel that predispose it to CD such as bacterial overgrowth in the small bowel that increases intestinal permeability, luminal changes in the colon that induce epithelial irritation or injury (distension, surfactant activity, and organic acid production), and the induction of selective bacterial proliferation as a prebiotic effect. 
Taken together, these findings could constitute a target for improving symptoms and reducing current reliance on drug therapy. Recently, exclusion of FODMAPS from the diet has been shown to improve functional gut symptoms in patients with IBD (96). However, further studies are required.

\section{Exogenous microparticle hypothesis}

Another dietary factor that seems to be implicated in the etiopathogenesis of IBD and particularly that of CD is exogenous dietary microparticles (97). These are defined as non-biological particles of the gastrointestinal lumen with an appropriate size and shape which are taken up by mucosal phagocytes. They appear to be almost exclusively food additives, pharmaceuticals, and toothpaste (aluminosilicates, titanium dioxide, and non-aluminum containing silicates). These exogenous microparticles first absorb certain antigenic luminal materials such as pathogen-associated molecular patterns (PAMPs) and then carry these PAMPs (lipopolysaccharides) to the intestinal tissue via M-cells. In this way, the microparticles seem to establish abnormal immune responsiveness by inducing intestinal immune activity and reducing the physiological immune tolerance of the intestinal mucosa. In fact, some data show that microparticle-conjugates/ agglomerates may exacerbate inflammation in the permeable and hyperresponsive gut of patients with IBD. A pilot study showed that the withdrawal of microparticles from the diet of CD patients was associated with an improvement in symptoms (98). However, a large multi-centre, double-blind trial found no effect on disease activity (99). In conclusion, the role and possible clinical implication of microparticles in IBD remains elusive.

\section{Nutrigenomics and IBD}

Considering recent findings concerning the implication of certain genetic mutations in the pathogenesis of IBD, current nutrigenetic and nutrigenomic approaches are worth noting $(100,101)$. Dietary components can alter certain types of gene expression under a normal and variable genetic status to thus become either risk or protective factors for disease development (101). For example, multidrug resistance 1 (MDR1) is a probable IBD susceptibility gene that encodes a P-glycoprotein (170 kDa). It is vulnerable to inhibition, activation, or induction by various herbal constituents. In fact, while curcumin, ginsenosides, and piperine were all found to inhibit P-glycoprotein, some catechins from green tea were found to be activators of P-glycoprotein-mediated drug transport (102). Furthermore, nutrigenomic approaches utilize knowledge about the genes involved in disease susceptibility in order to design diets that may potentially overcome the disorder. Some studies developed a specific cell-based assay to test the ability of food components or extracts to overcome the functional effects of certain variant SNPs that may be important in IBD (NOD2 3020insC) (103). These approaches could lead clinicians to develop a personalized nutritional prescription based on individual genetic variations to address phenotype modifications in IBD patients. However, the role of nutrient-gene interaction in the treatment of IBD patients remains to be established and must be addressed in future clinical studies.

\section{CONCLUSION AND WAY FORWARD}

Nutritional therapies can be divided into support nutritional therapy and primary nutritional therapy to induce and maintain remission. Up until now, the use of nutritional treatment as primary therapy has been controversial and the results are less impressive than those achieved using corticosteroid therapy in adult IBD patients, although there is some evidence of its usefulness in the maintenance of remission in adult $C D$ patients. In contrast, nutritional therapy is considered to be a first-line therapy for active CD in children, causing mucosal healing and demonstrating an efficacy equal to that of steroids.

At present there are no universally accepted recommendations on whether one specific type of formula composition should be routinely used over another. Well-powered studies are thus needed to evaluate the efficacy of formulas enriched with active biological factors such as TGF$\beta_{2}$ which can directly influence the intestinal immune response by restoring the physiological tolerance of the intestinal mucosa. In the future, research on these formula compositions should be developed in order to evaluate their role as primary or adjunctive treatments.

Nutritional therapy has been used in IBD with various individual response results. While the role of nutrient-gene interaction remains unclear in IBD patients, it is important to emphasize that diet is a factor which is always present in the management of IBD, either as conventional food intake or specific nutritional therapy. In light of currently available data, future research will have to consider the potential role of nutrient-gene interaction in drug trials and specific dietary formula compositions.

Finally, emerging knowledge about the etiopathogenesis of IBD provides an important opportunity to discover a potential new role for dietary factors in order to develop new formula compositions and identify new dietary risk factors. This should contribute to a fruitful relationship between clinical and basic scientific approaches in the management of IBD patients.

\section{REFERENCES}

1. Lochs H, Dejong C, Hammarqvist F, Hebuterne X, Leon-Sanz M, Schütz T, et al. ESPEN Guidelines on Enteral Nutrition: Gastroenterology. Clin Nutr 2006;25:260-74. 
2. Van Gossum A, Cabre E, Hébuterne X, Jeppesen P, Krznaric Z, Messing B, et al. ESPEN Guidelines on Parental Nutrition: Gastroenterology. Clin Nutr 2009;28:415-27.

3. Hartman C, Eliakim R, Shamir R. Nutritional status and nutritional therapy in inflammatory bowel diseases. World J Gastroenterol 2009; 15:2570-8.

4. Lanfranchi GA, Brignola C, Campieri M, Bazzocchi G, Pasquali R, Bassein L. Assessment of nutritional status in Crohn's disease in remission or low activity. Hepatogastroenterology 1984;31:129-32.

5. Sawczenko A, Sandhu BK. Presenting features of inflammatory bowel disease in Great Britain and Ireland. Arch Dis Child 2003;8:995-1000.

6. O'Sallivan M, O'Morain. Nutrition in inflammatory bowel disease. Best Pract Res Clin Gastroenterol 2006;20:561-73.

7. Geerling BJ, Badart-Smook A, Stockbrugger RW, Brummer RJ. Comprehensive nutritional status in recently diagnosed patients with inflammatory bowel disease compared with population controls. Eur J Clin Nutr 2000;54:514-21.

8. Rocha R, Santana GO, Almeida N, Lyra AC. Analysis of fat and muscle mass in patients with inflammatory bowel disease during remission and active phase. Br J Nutr 2009;101:676-9.

9. Seidman E, LeLeiko N, Ament M, Berman W, Caplan D, Evans J, et al. Nutritional issue in paediatric inflammatory bowel disease. J Pediatr Gastroenterol Nutr 1991;12:424-38.

10. Sentongo TA, Semeao EJ, Piccoli DA, Stallings VA, Zemel BS. Growth, body composition and nutritional status in children and adolescents with Crohn's disease. J Pediatr Gastroenterol Nutr 2000;31:33-40.

11. Markowitz J, Grancher K, Rosa J, Aiges H, Daum F. Growth failure in pediatric inflammatory bowel disease. J Pediatr Gastroenterol Nutr 1993; 16:373-80.

12. Higgens CS, Keighley MR, Allan RN. Impact of preoperative weight loss and body composition changes on postoperative outcome in surgery for inflammatory bowel disease. Gut 1984;25:732-6.

13. Card T, Hubbard R, Logan RFA. Mortality in inflammatory bowel disease: a population-based cohort study. Gastroenterology 2003;125:158390.

14. Lucendo AJ, De Rezende LC. Importance of nutrition in inflammatory bowel disease. World J Gastroenterol 2009;15:2081-8.

15. Lashner BA, Evans AA, Hanauer SB. Preoperative total parenteral nutrition for bowel resection in Crohn's disease. Dig Dis Sci 1989; 34:741-6.

16. Gouma DJ, Von Meyenfeldt MF, Rouflart M, Soeters PB. Preoperative total parenteral nutrition (TNP) in severe Crohn's disease. Surgery 1988;103:648-52.

17. Shiloni E, Coronado E, Freund HR. Role of total parental nutrition in the treatment of Crohn's disease. Am J Surg 1989;157:180-5.

18. Yao GX, Wang XR, Jiang ZM, Zhang SY, Ni AP. Role of perioperative parenteral nutrition in severely malnourished patients with Crohn's disease. World J Gastroenterol 2005;11:5732-4.

19. Harries AD, Jones LA, Danis V, Fifield R, Heatley RV, Newcombe $\mathrm{RG}$, et al. Controlled trial of supplemented oral nutrition in Crohn's disease. Lancet 1983;1:887-90.

20. Aiges H, Markowitz J, Rosa J, Daum F. Home nocturnal supplemental nasogastric feedings in growth-retarded adolescents with Crohn's disease. Gastroenterology 1989;97:905-10.

21. Belli DC, Seidman E, Bouthillier L, Weber AM, Roy CC, Pletincx M, et al. Chronic intermittent elemental diet improves growth failure in children with Crohn's disease. Gastroenterology 1988;94:603-10.

22. Motil KJ, Grand RJ, Davis-Kraft L, Ferlic LL, Smith EO. Growth failure in children with inflammatory bowel disease: a prospective study. Gastroenterology 1993;105:681-91.

23. Driscoll RH, Rosenberg IH. Total parenteral nutrition in inflammatory bowel disease. Med Clin North Am 1978; 62: 185-201.

24. Seidman EG. Nutritional management of inflammatory bowel disease. Gastroenterol Clin North Am 1989;18:129-55.

25. Andreassen H, Rix M, Brot C, Eskildsen P. Regulators of calcium homeostasis and bone mineral density in patients with Crohn's disease. Scand J Gastroenterol 1998;33:1087-93.

26. Andreassen H, Rungby J, Dahlerup JF, Mosekilde L. Inflammatory bowel disease and osteoporosis. Scand J Gastroenterol 1997;32:124755 .

27. Vogelsang H, Ferenci P, Resch H, Kiss A, Gangl A. Prevention of bone mineral loss in patients with Crohn's disease by long-term oral vitamin D supplementation. Eur J Gastroenterol Hepatol 1995;7:609-14.
28. Bendix-Struve M, Bartels LE, Agnholt J, Dige A, Jørgensen SP, Dahlerup JF. Vitamin D3 treatment in Crohn's disease patients increases stimulated T cell IL-6 production and proliferation. Aliment Pharmacol Ther 2010;32:1364-72

29. García-Manzanares Vázquez de Agredos A, Álvarez Hernandez J, Maqueda Villaizan E. Soporte nutricional en la enfermedad inflamatoria intestinal. In: Bellido D, De Luis D, editors. Manual de Nutrición y Metabolismo. Madrid: Díaz de Santos; 2006. p. 333-48.

30. Goh J, O'Morain CA. Review article: nutrition and adult inflammatory bowel disease. Aliment Pharmacol Ther 2003;17:307-20.

31. Lashner BA. Red blood cell folate is associated with the development of dysplasia and cancer in ulcerative colitis. J Cancer Res Clin Oncol 1993;119:549-54.

32. Geerling BJ, Stockbrügger RW, Brummer RJ. Nutrition and inflammatory bowel disease: an update. Scand J Gastroenterol Suppl 1999;230:95-105.

33. Thornton JR, Emmett PM, Heaton KW. Smoking, sugar, and inflammatory bowel disease. Br Med J (Clin Res Ed) 1985;290:1786-7.

34. Talbot RW, Heppell J, Dozois RR, Beart RW Jr. Vascular complications of inflammatory bowel disease. Mayo Clin Proc 1986;61:140-5.

35. Wild GE, Drozdowski L, Tartaglia C, Clandinin MT, Thomson ABR. Nutritional modulation of the inflammatory response in inflammatory bowel disease-from the molecular to the integrative to the clinical. World J Gastroenterol 2007;13:1-7.

36. Scolapio JS. The role of total parenteral nutrition in the management of patients with acute attacks of inflammatory bowel disease. J Clin Gastroenterol 1999;29:223-4.

37. McIntyre PB, Ritchie JK, Hawley PR, Bartram CI, Lennard-Jones JE. Management of enterocutaneous fistula: a review of 132 cases. Br J Surg 1984;71:293-6.

38. Ostro MJ, Greenberg G, Jeejeebhoy KN. Total parenteral nutrition and complete bowel rest in the management of Crohn's disease. JPENN J Parenter Enteral Nutr 1985;9:280-7.

39. Greenberg GR, Fleming CR, Jeejeebhoy KN, Rosenberg IH, Sales D, Tremaine WJ. Controlled trial of bowel rest and nutritional support in the management of Crohn's disease. Gut 1988;29:1309-15.

40. Bannerjee K, Camacho-Hübner C, Babinsk K, Dryhurst KM, Edwards $\mathrm{R}$, Savage MO, et al. Anti-inflammatory and growth-stimulating effects precede nutritional restitution during enteral feeding in Crohn's disease. J Pedriat Gastroenterol Nutr 2004;38:270-5.

41. Wilson DC, Thomas AG, Croft NM, Newby E, Akobeng A, Sawczenko A, et al. Systematic review of the evidence base for the medical treatment of paediatric inflammatory bowel disease. J Pediatr Gastroenterol Nutr 2010;50:S14-S34.

42. Fernandez-Banares F, Cabre E, Esteve-Comas M, Gassull MA. How effective is enteral nutrition in inducing clinical remission in active Crohn's disease? A meta-analysis of the randomized clinical trials. JPEN J Parenter Enteral Nutr 1995;19:356-64.

43. Griffiths AM, Ohlsson A, Sherman PM, Surtherland LR. Meta-analysis of enteral nutrition as a primary treatment of active Crohn's disease. Gastroenterology 1995;108:1056-67.

44. Messori A, Trallori G, D’ Albrasio G, Milla M, Vannozzi G, Pacini F. Defined-formula diets versus steroids in the treatment of active Crohn's disease: a meta-analysis. Scand J Gastroenterol 1996;31:26772.

45. Zachos M, Tondeur M, Griffiths AM. Enteral nutritional therapy for inducing remission of Crohn's disease. Cochrane Database Syst Rev 2001;CD000542.

46. Zachos M, Tondeur M, Griffiths AM. Enteral nutritional therapy for induction of remission in Crohn's disease. Cochrane Database Syst Rev 2007;CD000542.

47. Hartman C, Eliakim R, Shamir R. Nutritional status and nutritional therapy in inflammatory bowel diseases. World J Gastroenterol 2009;15:2570-8

48. Bremner AR, Beattie R. Therapy of Crohn's disease in childhood. Expert Opin Pharmacother 2002;3:809-25.

49. Fell JM, Paintin M, Arnaud-Battandier F, Beattie RM, Hollis A, Kitching $\mathrm{P}$, et al. Mucosal healing and a fall in mucosal pro-inflammatory cytokine mRNA induced by a specific oral polymeric diet in paediatric Crohn's disease. Alimet Pharmacol Ther 2000;14:281-9.

50. Heuschkel RB, Menacne CC, Megerian JT, Baird AE. Enteral nutrition and corticosteroids in the treatment of acute Crohn's disease in children. J Pediatr Gastroenterol Nutr 2000;31:8-15. 
51. Johnson T, Macdonald S, Hill SM, Thomas A, Murphy MA. Treatment of active Crohn's disease in children using partial enteral nutrition with liquid formula: a randomised controlled trial. Gut 2006;55:356-61.

52. Ludvigsson JF, Krantz M, Bodin L, Stenhammar L, Lindquist B. Elemental versus polymeric enteral nutrition in paediatric Crohn's disease: a multicentre randomized controlled trial. Acta Pediatr 2004:93:327-35.

53. Knight C, El-Matary W, Spray C, Sandhu BK. Long-term outcome of nutritional therapy in paediatric Crohn's disease. Clin Nutr 2005;24:7759.

54. Berni Canani R, Terrin G, Borrelli O, Romana MTR, Manguso F, Coruzzo A, et al. Short- and long-term therapeutic efficacy of nutritional therapy and corticosteroids in paediatric Crohn's disease. Dig Liver Dis 2006;38:381-7.

55. Buchanan E, Gaunt WW, Cardigan T, Garrick V, McGrogan P, Russell $\mathrm{RK}$. The use of exclusive enteral nutrition for induction of remission in children with Crohn's disease demonstrates that disease phenotype does not influence clinical remission. Aliment Pharmacol Ther 2009;30:501-7.

56. Esaki M, Matsumoto T, Nakamura S, Yada S, Fujisawa K, Jo Y, et al. Factors affecting recurrence in patients with Crohn's disease under nutritional therapy. Dis Colon Rectum 2006;49:S68-4

57. Verma S, Kirkwood B, Brown S, Giaffer MH. Oral nutritional supplementation is effective in the maintenance of remission in Crohn's disease. Dig Liver Dis 2000:32:769-74.

58. Wilschanski M, Sherman P, Pencharz P, Davis L, Corey M, Griffiths A. Supplementary enteral nutrition maintains remission in paediatrics Crohn's disease. Gut 1996;38:543-8.

59. Hirakawa H, Fukuda Y, Tanida N, Hosomi M, Shimoyama T. Home elemental enteral hyperalimentation (HEEH) for the maintenance of remission in patients with Crohn's disease. Gastroenterol Jpn 1993; 28:379-84.

60. Akobeng AK, Thomas AG. Enteral nutrition for maintenance of remission in Crohn's disease. Cochrane Database Syst Rev 2007;CD005984.

61. Takagi S, Utsunomiya K, Kuriyama S, Yokoyama H, Takahashi S, Iwabuchi M, et al. Effectiveness of an 'half elemental diet' as maintenance therapy for Crohn's disease: a randomized-controlled trial. Aliment Parmacol Ther 2006;24:1333-40.

62. Yamamoto T, Nakahigashi M, Saniabadi AR, Jwata T, Maruyama Y, Umegae S, et al. Impacts of long-term, enteral nutrition on clinical and endoscopic disease activities and mucosal cytokines during remission in patients with Crohn's disease: a prospective study. Inflamm Bowel Dis 2007;13:1493-501.

63. Buchman AL. Glutamine for the gut: mystical properties or an ordinary amino acid? Curr Gastroenterol Rep 1999;1:417-23.

64. Den Hond E, Hiele M, Peeters M, Ghoos Y, Rutgeerts P. Effect of longterm oral glutamine supplements on small intestinal permeability in patients with Crohn's disease. JPEN J Parenter Enteral Nutr 1999;23:711.

65. Akobeng AK, Miller V, Stanton J, Elbadri AM, Thomas AG. Doubleblind randomized controlled trial of glutamine-enriched polymeric diet in the treatment of active Crohn's disease. J Ped Gastroenterol Nutr 2000;30:78-84

66. Ockenga J, Borchert K, Stuber E, Lochs H, Manns MP, Bischoff SC. Glutamine-enriched total parenteral nutrition in patients with inflammatory bowel disease. Eur J Clin Nutr 2007;59:1302-9.

67. Gorard DA. Enteral nutrition in Crohn's disease: fat in the formula. Eur J Gastroenterol Hepatol 2003;15:115-8.

68. Gassull MA, Fernandez-Banares F, Cabre E, Papo M, Giaffer MH, Sánchez-Lombraña, et al. Fat composition may be a clue to explain the primary therapeutic effect on enteral nutrition in Crohn's disease: results of a double blind randomised multicentre European trial. Gut 2002; 51:164-8.

69. Bamba T, Shimoyama T, Saaki M, Tsujikawa T, Fukuda Y, Koganei $\mathrm{K}$, et al. Dietary fat attenuates the benefits of an elemental diet in active Crohn's disease: a randomized, controlled trial. Eur J Gastroenterol Hepatol 2003;15:151-7

70. Varnalidis I, Ioannidis O, Karamanavi E, Ampas Z, Poutahidis T, Taitzoglou I, et al. Omega 3 fatty acids supplementation has an ameliorative effect in experimental ulcerative colitis despite increased colonic neutrophil infiltration. Rev Esp Enferm Dig 2011;103:511-8.

71. Turner D, Zlotkin SH, Shah PS, Griffiths AM. Omega 3 fatty acids (fish oil) for maintenance of remission in Crohn's disease. Cochrane Database Syst Rev 2007;CD006320.
72. Senagore AJ, Mackeigan JM, Scheider M, Ebrom JS. Short-chain fatty acid enemas: a costeffective alternative in the treatment of nonspecific proctosigmoiditis. Dis Colon Rectum 1992;35:923-7.

73. Lorenz-Meyer H, Bauer P, Nicolay C, Schulz B, Purrmann J, Fleig WE, et al. Omega 3 fatty acids and low carbohydrate diet for maintenance of remission in Crohn's disease. A randomized controlled multicenter trial. Study Group Members (German Crohn's Disease Study Group). Scand J Gastroenterol 1996;31:778-85.

74. Nieves R, Jackson RT. Specific carbohydrate diet in treatment of inflammatory bowel disease. Tenn Med 2004;97:407.

75. Beattie RM, Schiffrin EJ, Donnet-Hughes A, Huggett AC, Domizio P, MacDonald TT, et al. Polymeric nutrition as the primary therapy in children with small bowel Crohn's disease. Aliment Pharmacol Ther 1994;8:609-15

76. Fell JM, Paintin M, Arnaud-Battandier F, Beattie RM, Hallis A. Kitching P, et al. Mucosal healing and a fall in mucosal pro-inflammatory cytokine mRNA induced by specific oral polymeric diet in paediatric Crohn's disease. Aliment Pharmacol Ther 2000;14:2819.

77. Afzal NA, Van der Zaag-Loonen HJ, Arnaud-Battandier F, Davies S, Murch S, Derkx B, et al. Improvement in quality of life of children with acute Crohn's disease does not parallel mucosal healing after treatment with exclusive enteral nutrition. Aliment Pharmacol Ther 2004;20:167-72.

78. Riordan AM, Hunter JO, Cowan RE, Crampton JR, Davidson AR, Dickinson RJ, et al. Treatment of active Crohn's disease by exclusion diet: Esat Anglian multicentre controlled trial. Lancet 1993;342:11314.

79. Pearson M, Teahon K, Levi AJ, Bjarnason I. Food intolerance and Crohn's disease. Gut 1993;34:783-7.

80. Jones VA, Dickinson RJ, Workman E, Wilson AJ, Freeman AH, Hunter JO. Crohn's disease: maintenance of remission by diet. Lancet $1985 ; 2: 177-80$

81. Huber A, Genser D, Spitzauer S, Scheiner O, Jensen-Jarolim E. IgE/anti-IgE immune complexes in sera from patients with Crohn's disease do not contain food-specific IgE. Int Arch Allergy Immunol 1998; $115: 67-72$

82. Mekkel G, Barta Z, Ress Z, Gyimesi E, Sipka S, Zeher M. Increased IgE-type antibody response to food allergens in irritable bowel syndrome and inflammatory bowel diseases. Orv Hetil 2005;146:797802.

83. Elmgreen J, Stahl Skov P, Permin H, Binder V, Heugh Wandall J, Norn S. Type I allergy to normal cellular constituents in chronic inflammatory bowel disease? Results from basophil histamine release test compared with total IgE and antinuclear antibodies. Allergy 1984:39:23-8.

84. Bentz S, Hausmann M, Piberger H, Kellermeier S, Paul S, Held L, et al. Clinical relevance of IgG antibodies against food antigens in Crohn's disease: a double-blind cross-over diet intervention study. Digestion 2010;81(4):252-64.

85. Danese S, Fiocchi C. Aetiopathogenesis of inflammatory bowel diseases. World J Gastroenterol 2006; 12:4807-12.

86. Gentschew L, Ferguson LR. Role of nutrition and microbiota in susceptibility to inflammatory bowel diseases. Mol Nutr Food Res 2012;56:524-35

87. Bibiloni R, Fedorak RN, Tannock GW, Madsen KL, Gionchetti P, Campieri M, De Simone C, Sartor RB. VSL\#3 probiotic-mixture induces remission in patients with active ulcerative colitis. Am J Gastroenterol 2005;100:1539-46.

88. Chapman TM, Plosker GL, Figgitt DP. VSL\#3 probiotic mixture: a review of its use in chronic inflammatory bowel diseases. Drugs 2006:66:1371-87.

89. Chapman MA. The role of the colonic flora in maintaining a healthy large bowel mucosa. Ann R Coll Surg Engl 2001;83:75-80.

90. Steinhart AH, Hiruki T, Brzezinski A, Baker JP. Treatment of leftsided ulcerative colitis with butyrate enemas: a controlled trial. Aliment Pharmacol Ther 1996;10:729-36.

91. Assumpção IR, Rodrigues M, Barbieri D. Treatment of unspecific ulcerative rectocolitis in a child with enemas containing butyrate. Case report. Arq Gastroenterol 1999;36:238-43.

92. Farrokhyar F, Swarbrick ET, Irvine EJ. A critical review of epidemiological studies in inflammatory bowel disease. Scand J Gastroenterol 2001;36:2-15. 
93. Sands BE. Inflammatory bowel disease: past, present and future. J Gastroenterol 2007; 42:16-25.

94. Gibson PR, Shepherd SJ. Personal view: food for thought-western lifestyle and susceptibility to Crohn's disease. The FODMAP hypothesis. Aliment Pharmacol Ther 2005;21:1399-409.

95. Meddings JB, Gibson PR, Tagkalidis P. Mucosal defense and intestinal permeability. In: Satsangi J, Sutherland LR eds. Inflammatory Bowel Diseases. Edinburgh: Churchill Livingstone; 2003. p. 63-83.

96. Gearry RB, Irving PM, Barrett JS, Nathan DM, Shepherd SJ, Gibson PR. Reduction of dietary poorly absorbed short-chain carbohydrates (FODMAPs) improves abdominal symptoms in patients with inflammatory bowel disease-a pilot study. J Crohns Colitis 2009;3:8-14.

97. Powell JJ, Thoree V, Pele LC. Dietary microparticles and their impact on tolerance and immune responsiveness of the gastrointestinal tract. Br J Nutr 2007;98(Supl. 1):S59-S63.
98. Lomer MC, Harvey RS, Evans SM, Thompson RP, Powell JJ. Efficacy and tolerability of a low microparticle diet in a double blind, pilot study in Crohn's disease. Eur J Gastroenterol Hepatol 2001;13:101-6.

99. Lomer MC, Grainger SL, Ede R, Catterall AP, Greenfield SM, Cowan $\mathrm{RE}$, et al. Lack of efficacy of a reduced microparticle diet in a multicentred trial of patients with active Crohn's disease. Eur J Gastroenterol Hepatol 2005; 17:377-84.

100. Cho JH. The genetics and immunopathogenesis of inflammatory bowel disease. Nat Rev Immunol 2008;8:458-66.

101. Lee G, Buchman AL. DNA-driven nutritional therapy of inflammatory bowel disease. Nutrition 2009;25:885-91.

102. Zhous S, Lim LY, Chowbay B. Herbal modulation of P-glycoprotein Drug Metab Rev 2004;36:57-104.

103. Philpott M, Mackay L, Ferguson LR, Forbes D, Skinner M. Cell culture models in developing nutrigenomics foods for inflammatory bowel disease. Mutat Res 2007;622:94-102. 